\title{
The Economics of EBIPM on Great Basin Rangelands
}

\author{
By Kimberly Rollins and Michael H. Taylor
}

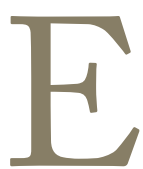

cologically Based Invasive Plant Management (EBIPM) has been shown to be more effective at rehabilitating sagebrush rangeland degraded by invasive plants than standard invasive plant management practices. ${ }^{1,2,3}$ The improvements in ecosystem function that result from implementing EBIPM on sagebrush rangelands have numerous economic benefits, from increased forage productivity for domestic livestock to enhancements in ecosystem goods and services (EGS), such as wildfire habitat and hydrological function. In this article, we describe how the economic benefits of EBIPM can be measured as the change in the flow of EGS resulting from improvements in ecosystem function, and highlight three recent research projects that have quantified the economic benefits of EBIPM on sagebrush rangelands using this approach.

Quantifying the economic benefits of EBIPM requires adopting a scientifically valid ecological framework that enables systematic comparisons of how a site would evolve over time with and without an invasive plant management treatment. The economic benefits of EBIPM can then be measured as the difference in flows of EGS under the two alternative ecological trajectories for the site. The three projects we discuss use economic models that incorporate a stylized version of the state-and-transition model framework. ${ }^{4} \mathrm{We}$ demonstrate that this framework is appropriate for evaluating the economic benefits of EBIPM on sagebrush rangelands in a variety of settings, and has the flexibility to evaluate both the economic benefits of preventing undesirable ecological change as a result of invasive plants and of rehabilitating rangeland degraded by invasive plants.

All three projects quantify the economic benefits of EBIPM in terms of improvements in each of the three categories of rangeland EGS described in Maczko et al: ${ }^{5}$ 1) "tangible extracted goods." such as forage for livestock; 2) "tangible in situ services (and disservices)." such as outdoor recreation or flood control; and 3) "intangible in situ services." such as the enhanced wellbeing derived by individuals from the knowledge that wildlife populations are healthy and thriving. We demonstrate that it is possible to quantify in dollars rangeland EGS from each of these three categories using economic methods applied to a scientifically valid ecological framework that focuses on transitions between states. In so doing, we add support to the argument by Maczko et al. ${ }^{5}$ that monetizing the diverse benefits that flow from rangeland ecological processes is technically feasible and should be on the agenda of applied agricultural and resource economists.

\section{Stylized State-and-Transition Model for Great Basin Rangelands}

Sagebrush rangelands cover over 100 million acres of high desert in the western United States, provide wildlife habitat and livestock forage, and support one of the fastest-growing human populations in the country. ${ }^{6}$ These systems are undergoing rapid ecological change as a result of invasive annual grasses and an acceleration of rangeland fire cycles that has led to increasingly severe and frequent wildfires. These ecological changes have increased wildfire suppression costs, degraded hydrologic function, and threaten to permanently impair the ability of sagebrush rangelands to support native wildlife and plants. It has been argued that the ecological change brought about by invasive plants might ultimately undermine the ecological and economic stability of the entire region. $7,8,9$

Some of the most productive sagebrush rangelands in the region are in the Wyoming Sagebrush Steppe (WSS) system. The WSS system is generally found at elevations of between 4,700 and 6,500 feet, covering roughly 37.8 million acres of the Great Basin (26\% of the 145 million acre Great Basin). ${ }^{i}$ Figure 1 illustrates a stylized version of a state-and-transition model for the WSS system developed by Taylor et al. ${ }^{10}$ In a recent paper, ${ }^{11}$ we described how the state-and-transition framework can be used to value ecosystem change on sagebrush rangelands, using economic models that incorporate rangeland ecosystem dynamics and stochastic wildfire, and that are applicable at spatial scales relevant for policy analysis on rangeland ecosystems in the western United States.

'Acreages based on Great Basin Restoration Initiative data (http:// sagemap.wr.usgs.gov). 


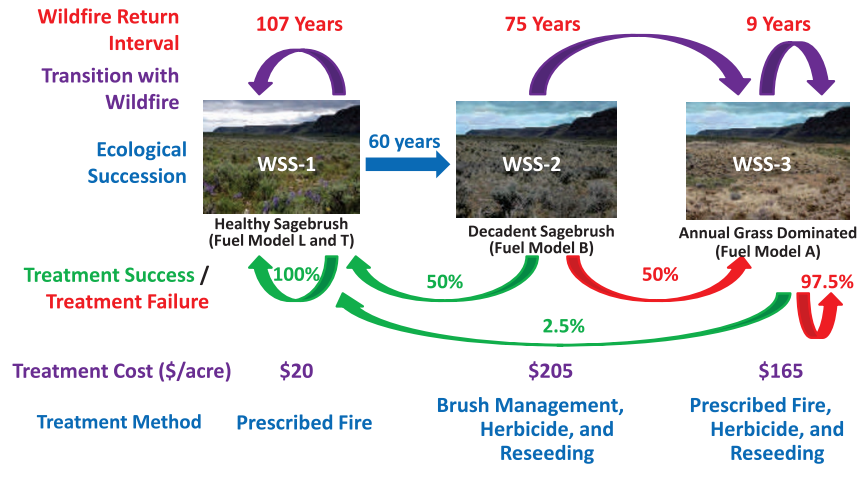

Figure 1. Stylized state-and-transition model, Wyoming Sagebrush Steppe (4,700-6,500 feet).

In Figure 1, the WSS system can potentially exist in one of three states, WSS1, WSS2, and WSS3. Invasive grasses are assumed to be present in the seed bank in all three states. Native perennial grasses, forbs, and shrubs are dominant in WSS1. Treatments for invasive annual grasses in WSS1 are relatively inexpensive and are generally effective at maintaining a healthy ecosystem that is resilient to disturbance. Given disturbances such as grazing, drought, and invasive plants, the system will eventually transition to WSS2, which is characterized by decadent sagebrush with invasive grasses dominant in the understory. A wildfire in WSS2 is likely to cause the system to transition to WSS3, a low-productivity, invasive annual grass-dominated state.

\section{Categories of Rangeland Ecosystem Goods and Services}

Maczko et al..$^{5}$ describe three categories of rangeland EGS. "Tangible extracted goods" are defined as productive inputs, such as forage, food, and fiber, which become available through extractive economic activities and are then combined with other inputs to generate goods with market value. The value of these tangible extracted goods can be estimated as the marginal value that each adds to the value of the final product. For example, the value of a change in forage availability as a result of transition from WSS1 to WSS2 could be measured as a change in profit of a ranching operation from that transition.

"Tangible in situ services (and disservices)" are defined as ecosystem services that provide value (or costs) to society through direct on-site interactions with rangeland ecosystems, as opposed to off-site extraction after removal. Recreational opportunities, water quality and quantity, and flood control are examples of in situ tangible services. Wildfire severity, wind and water erosion, and air quality impacts from dust and smoke are examples of in situ disservices that impose costs to society. For example, the present value of long-run wildfire suppression costs averted because an EBIPM program prevents a site in WSS1 from transitioning to WSS2 or WSS3 is a measure of in situ tangible disservices.

"Intangible in situ services" are nonmonetary enhancements to human wellbeing that occur as a result of direct or indirect interaction with rangelands. The enhanced wellbeing experienced by humans from the knowledge that a sensitive wildlife habitat is intact and can support native birds and animals is an intangible in situ service, as are the scenic beauty of healthy rangeland landscapes, cultural heritage of archeological sites, and western traditions supported by rangelands. Humans do not need to extract or remove materials to receive intangible in situ service benefits, nor do the benefits experienced by one user necessarily limit the benefits that others can enjoy. Nonmarket valuation methods, such as contingent valuation, are used to estimate people's values for in situ intangible services.

EGS from all three categories vary systematically between ecological states in sagebrush rangeland ecosystems. The three case studies we discuss below evaluate the economic benefits and costs associated with the changes in the flows of these EGS that take place when these ecosystems transition between ecological states. The estimates from these studies can then be used to estimate the economic benefits of EBIPM in circumstances where management is aimed at either preventing a transition to, or rehabilitating a site from, a degraded ecological state.

\section{Tangible Extracted Goods Case Study: Returns to Private Ranch Operations}

The benefit of rangeland forage to livestock operations is an example of the value of a "tangible extracted good." Kobayshi et al. ${ }^{12}$ developed an economic model of a cow-calf ranch operating on Great Basin rangelands and use it to consider a rancher's private incentives to perform invasive plant management. In this model, a rancher manages his/her ranch in order to maximize current and future ranching profits. The model focuses on the interrelated decisions of herd management and invasive plant management treatments. The rancher is assumed to consider the impact of their herd management and invasive species treatment decisions on future herd size and forage availability. The rancher does not know, however, when a wildfire will occur or how big the wildfire will be at the time these decisions are made. The model in Koybashi et al. ${ }^{12}$ incorporates the three-state WSS system depicted in Figure 1.

Results indicate that it is privately optimal for the rancher to undertake invasive plant management when the land on the ranch is in WSS1. This result is robust for a range of treatment costs, treatment success rates, cattle prices, and feed costs. Optimal herd size is larger and more stable (less extreme annual fluctuations) in WSS1 than in WSS2 because more forage is available on WSS1 than WSS2, and because wildfires in WSS1 are smaller and less frequent, so the rancher is less likely to reduce his herd size in response to temporary losses in grazing acreage following a wildfire. Although it is not optimal for the private rancher to pursue invasive plants management treatments in WSS2 under the baseline assumptions, these treatments become optimal in WSS2 at treatment success rates of over $90 \%$ and low treatments 
costs ( $\$ 20$ per acre). In addition, the model predicts that the rancher will liquidate their herd and close their operation if the land on their ranch moves to WSS3.

In addition, Koybashi et al. ${ }^{12}$ contrast the results for the private rancher with the results assuming socially efficient ranch management that takes into account wildfire suppression costs (a tangible in situ disservice) generally borne by public agencies, and nonmarket benefits that flow from healthy rangeland to the general public (an intangible in situ service), as well as private profits from ranching (a tangible extracted good). The contrast between private and socially efficient ranch management illustrates that the benefits of EBIPM extend beyond the direct benefits to private ranchers, and that policies to promote invasive plant management by private ranchers are likely to generate social benefits. The most striking result is that incentives to perform invasive plants management treatments are not as strong for the private rancher as they would be if the private rancher also took into account nonmarket benefits from rangeland health and wildfire suppression costs when making management decisions.

\section{Tangible In Situ Service Case Study: Wildfire Suppression Costs Averted}

Increases in wildfire severity and frequency on rangelands with plant communities dominated by invasive annual grasses are examples of "tangible in situ" ecosystem disservices. Taylor et al. ${ }^{10}$ implement a model to estimate the value of invasive plant management treatments in terms of the expected differences in wildfire suppression costs with and without treatment for the WSS.

In each year of the simulation model, wildfire occurrences, treatment success, and per acre wildfire suppression costs are random variables. Each run of the model considers the evolu- tion of the landscape with and without vegetation treatments over 200 years with different randomly generated realizations of these random variables in each year. Results are generated using 10,000 runs of the simulation model, and results are reported on a per acre basis, which allows the estimates of benefits and costs of vegetation treatments to be scaled up to larger spatial scales relevant for specific fuel management projects.

Table 1 reports results for the WSS system. Expected net fire suppression costs averted are $\$ 272$ per acre in WSS1, and treatment is not economically efficient in either WSS2 or WSS3. Treatments are economically efficient in the healthiest states because they are 100\% successful, relatively inexpensive, and prevent transitions to WSS2 and WSS3, which entail frequent wildfires that are expensive to suppress. Vegetation treatment is not economically efficient in WSS2 due to the cost (\$205 per acre) relative to expected benefits (\$133). An important reason why expected cost savings are low is that treatment in WSS2 is successful only $50 \%$ of the time and the consequences of treatment failure is that the system transitions to WSS3, which entails more frequent wildfires. This is reflected in that treatment in WSS2 only leads to a reduction in the number of wildfires from 15.2 to 12.1 over 200 years.

In WSS3, repeated application of vegetation treatment is effective at reducing wildfire suppression costs (\$139), but given the low probability of treatment success (2.5\%), treatment in WSS3 is cost-prohibitive. Treated land in WSS1 will always remain in WSS1; in contrast, without treatment, the model predicts that after 200 years, the systems will have transitioned to WSS2 7.3\% of the time and to WSS3 92.7\% of the time. This indicates that treatment in WSS1 serves to avoid the long-run conversion of the system to an annual grass-dominated state (WSS3). On the other hand, although

Table 1. Wyoming Sagebrush Steppe cost projection (net present value); values calculated using 10,000 runs, $\$$ per acre, 2010 dollars, 3\% discount rate, 200 years $(5 \%, 95 \%)$

\begin{tabular}{|c|c|c|c|}
\hline & \multicolumn{3}{|c|}{ Initial ecological state } \\
\hline & $\begin{array}{l}\text { Healthy sagebrush } \\
\text { (WSS 1) }\end{array}$ & $\begin{array}{l}\text { Mature woody brush } \\
\text { with annual grass } \\
\text { (WSS 2) }\end{array}$ & $\begin{array}{l}\text { Annual grass-dominated } \\
\text { (WSS 3) }\end{array}$ \\
\hline $\begin{array}{l}\text { Average total suppression } \\
\text { costs, no treatment }\end{array}$ & $\$ 350(\$ 0, \$ 1,141)$ & $\$ 364(\$ 0, \$ 1,219)$ & $\$ 390(\$ 150, \$ 703)$ \\
\hline $\begin{array}{l}\text { Average total suppression } \\
\text { costs, with treatment }\end{array}$ & $\$ 56(\$ 0, \$ 250)$ & $\$ 231(\$ 0, \$ 659)$ & $\$ 251(\$ 2.8, \$ 608)$ \\
\hline $\begin{array}{l}\text { Average suppression costs } \\
\text { saving net of treatment costs }\end{array}$ & $\$ 272(-\$ 24, \$ 1,022)$ & $-\$ 72(-\$ 636, \$ 728)$ & $-\$ 2,782(-\$ 4,965,-\$ 108)$ \\
\hline Average benefit/cost ratio & 13.3 & 0.7 & 0.06 \\
\hline
\end{tabular}




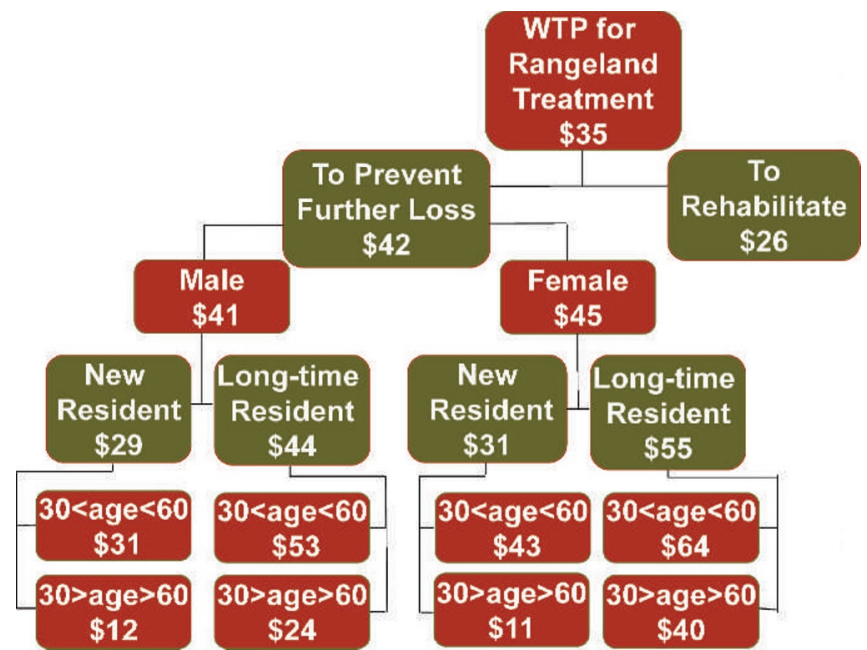

Figure 2. Annual household willingness to pay (WTP) by general public.

treated land in WSS2 and WSS3 can be rehabilitated to WSS1, it is still economically efficient for society to leave lands in these states rather than pursue rehabilitation from the perspective of reduced wildfire suppression expenditure.

Benefit/cost ratios are an appropriate metric for evaluating where to perform treatment on a landscape characterized by a mixture of different ecosystem types and ecological states, given a fixed budget. Given a fixed budget, net benefits are maximized by prioritizing individual parcels of land in descending order of benefit/cost ratio until the budget is exhausted. We find that the average benefit/cost ratio in WSS1 is 13.3, indicating that, based on wildfire suppression costs saving alone, land in WSS1should be given priority for fuel treatment.

Intangible in Situ Service Case Study: Willingness to Pay to Measure Ecosystem Benefits to the General Public

In another paper, Kobayashi and colleagues ${ }^{13}$ use the contingent valuation method to quantify the benefits of EBIPM in terms of the general public's willingness to pay to support invasive plant management programs that prevent Great Basin rangelands from transitioning to an invasive annual grass-dominated state. This study is an example of a method to estimate the benefits of invasive plant management that are derived from "intangible in situ services." Data were collected from a representative sample of Nevada residents via mail surveys who responded to two versions of a hypothetical proposed program to be funded through a dedicated tax for invasive plant management on public rangelands. The two versions describe 1) a program to rehabilitate areas that could no longer support native plants because of encroachment by invasive plants and 2) a program to prevent further areas from converting to states where they could no longer support native plants because of encroachment by invasive plants. The survey also describes the improvement/reductions in EGS that accompany these changes. In terms of our stylized stateand-transition model of the WSS system, the two versions of the survey ask respondents to either value the gains from rehabilitating a site from WSS3 to WSS1 or to value preventing the loses from the transition from WSS1 to WSS3.

Willingness to pay for the hypothetical programs is estimated using statistical methods that are based on the probabilities that an individual would respond with "definitely yes," "probably yes," "unsure," "probably no," and "definitely no" for ranges of annual expenses to their household that would be necessary to achieve and maintain the rangeland ecosystem change described in the hypothetical scenario (either to prevent further loss of rangeland to invasive annual grasses or to rehabilitate annual grass-dominated rangeland). Mean household annual willingness to pay for invasive plant management programs ranged from $\$ 35$ to $\$ 100$, depending on household characteristics. ${ }^{13}$ Examples of selected results related to gender, age, and length of residency in Nevada are summarized in Figure 2. A particularly interesting result is that rangeland invasive plant management programs that target preventing undesirable ecosystem change are more highly valued than those targeting rehabilitation. The difference in willingness to pay between prevention versus rehabilitation is due to the increased probability of a respondent opposing a rehabilitation program, rather than to higher willingness to pay for prevention programs. This suggests that timing of invasive plant management policy is important; with all else equal, the general public is willing to invest more to maintain healthy rangelands than it is to rehabilitate degraded rangelands. These results are reinforced by the results in the previous section that indicate that the returns from investment in invasive plant management as measured by wildfire suppression costs averted are greater when applied to "healthier" rangelands than to rehabilitating rangelands that have converted to invasive-plant-dominated states and can no longer support native plants.

\section{Conclusions and Implications for Policy and Management}

In this article, we emphasize the importance of economic analysis for adopting a scientifically valid ecological framework that enables modeling how a site would evolve over time with and without an invasive plant management treatment being implemented. The economic benefits of EBIPM in the first and second case study are measured by evaluating the difference in flows of ecosystems goods and services under the two alternative ecological trajectories with and without treatment. The three projects discussed in this article adopt a stylized version of the state-and-transition model framework from rangeland ecology. The state-and-transition model framework allows evaluation of the benefits of EBIPM related to preventing undesirable ecological change as a result of invasive plants and of rehabilitating rangeland degraded by invasive plants. The studies discussed in this article conclude that, in terms of wildfire suppression costs savings, the benefits of preventing undesirable ecological change outweigh those of rehabilitation, and that the general public has a much greater willingness to pay to support programs that prevent 
annual grass invasion on healthy rangelands compared to rehabilitation programs on invaded rangeland.

We also emphasize that the improvements in ecosystem function that result from the successful application of EBIPM treatments can influence multiple rangeland EGS and have a correspondingly large and diverse set of beneficiaries. It is possible to quantify many of these EGS in dollars using standard empirical techniques from environmental and resource economics. There is a strong argument for attempting to quantify as many rangeland EGS as possible, because if the benefits from a category of EGS are omitted, it is possible that they will be given less weight or even ignored in policy making. Moreover, quantifying the different categories of rangeland EGS is important because although the benefits of EBIPM for any one EGS might not be sufficient to justify the cost of treatment, it could be the case that the benefits outweigh the costs when multiple categories of benefits and groups of beneficiaries are considered.

\section{References}

1. Krueger-Mangold, J. M., R. L. Sheley, and T. J. Svejcar. 2006. Toward Ecologically-Based Invasive Plant Management on rangeland. Weed Science 54:597-605.

2. Morghan, K. J. R., R. L. Sheley, and T. J. Svejcar. 2006. Successful adaptive management: the integration of research and management. Rangeland Ecology Eं Management 59:216-219.

3. Sheley, R. L., J. M. Mangold, and J. L. Anderson. 2006. Potential for successional theory to guide restoration of invasive-plantdominated rangeland. Ecological Monographs 76:365-379.

4. Stringham, T. K., W. C. Krueger, and P. L. Shaver. 2003. State and transition modeling: an ecological process approach. Journal of Range Management 56:106-113.

5. Maczko, K., J. A. Tanaka, R. Breckenridge, L. Hidinger, H. T. Heintz, W. E. Fox, U. P. Kreuter, C. S. Duke, J. E. Mitchell, and D. W. McCollum. 2011. Rangeland ecosystem goods and services: values and evaluation of opportunities for ranchers and land managers. Rangelands 33(5):30-36.

6. Knick, S. T., D. S. Dobkin, J. T. Rotenberry, M. A. Schroeder, W. M. Vander Haegen, and C. van Riper III. 2003. Tee- tering on the edge or too late? Conservation and research issues for avifauna of sagebrush habitats. The Condor 105:611-634

7. US Department of the Interior. 1999. Out of ashes, and opportunity. Boise, ID, USA: US Department of the InteriorBureau of Land Management National Interagency Fire Center. $28 \mathrm{p}$.

8. US Department of the Interior. 2000. The Great Basin: healing the land. Boise, ID, USA: US Department of the Interior-Bureau of Land Management National Interagency Fire Center. 33 p.

9. Pellant, M., B. Abbey, and S. Karl. 2004. Restoring the Great Basin desert, U.S.A.: integrating science, management, and people. Environmental Monitoring and Assessment 99:169179.

10. Taylor, M., H. K. Rollins, M. Kobayashi, and R. Tausch. 2012. The economics of fuel management: wildfire, invasive plants, and the evolution of sagebrush rangelands in the western United States. Journal of Environmental Management (in review).

11. TAYlor, M. H., And K. Rollins. 2012. Using ecological models to coordinate valuation of ecological change on western rangelands for ex post application to policy analysis. Western Economics Forum 11:13-21.

12. Kobayashi, M., K. Rollins, and M. H. Taylor. 2010. Ranching, invasive annual grasses, and the external costs of wildfire in the Great Basin: a stochastic dynamic programming approach. Paper presented at the Agricultural and Applied Economics Association 2010 Annual Meeting; 25-27 July 2010; Denver, CO, USA. 39 p. Available at: http://purl.umn.edu/61869. Accessed 2 November 2012.

13. Kobayashi, M., K. Rollins, M. D. R. Evans. 2010. Sensitivity of WTP estimates to definition of 'yes': reinterpreting expressed response intensity. Agricultural and Resource Economics Review 39:37-55.

Authors are Associate Professor (Rollins) and Research Assistant Professor,mbtaylor@unr.edu (Taylor),Dept of Economics, University of Nevada, Reno, Reno, NV 89557, USA. 